\title{
Generating Benefits and Negotiating Tensions through an International Doctoral Forum: A Sociological Analysis
}

\author{
Guanglun Michael Mu \\ Queensland University of Technology, Brisbane, QId, Australia \& \\ Beijing Normal University, Beijing, China \\ m.mu@qut.edu.au
}

\author{
Ning Jia \\ Shenyang University, Shenyang, \\ Liaoning, China \\ jennings.jianing@qq.com \\ Hilary Hughes \\ Queensland University of \\ Technology, Brisbane, QId, Australia \\ h.hughes@qut.edu.au \\ Jennifer Alford and Merilyn Carter \\ Queensland University of \\ Technology, Brisbane, QId, Australia \\ jh.alford@qut.edu.au; \\ merilyn.carter@qut.edu.au \\ Jennifer Duke \\ Queensland University of \\ Technology, Brisbane, QId, Australia \\ jk.duke@qut.edu.au \\ Yongbin $\mathrm{Hu}$ \\ Jiangsu Normal University, Xuzhou, \\ Jiangsu, China \\ huyb@jsnu.edu.cn \\ Xiaobo Shi and Mu-chu Zhang \\ Beijing Normal University, \\ Beijing, China \\ 872270532@qq.com; \\ muchuchiang@126.com \\ Jillian Fox \\ Australian Catholic University, \\ Brisbane, QId, Australia \\ jillian.fox@acu.edu.au \\ Matthew Flynn \\ Well Grounded Consultancy, \\ Brisbane, QId, Australia \\ matt@wellgrounded.com.au

\section{Huanhuan Xia \\ Beijing Normal University, Beijing, China \\ xhh@bnu.edu.cn}

\footnotetext{
Material published as part of this publication, either on-line or in print, is copyrighted by the Informing Science Institute. Permission to make digital or paper copy of part or all of these works for personal or classroom use is granted without fee provided that the copies are not made or distributed for profit or commercial advantage AND that copies 1) bear this notice in full and 2) give the full citation on the first page. It is permissible to abstract these works so long as credit is given. To copy in all other cases or to republish or to post on a server or to redistribute to lists requires specific permission and payment of a fee. Contact Publisher@InformingScience.org to request redistribution permission.
} 


\section{Abstract}

Workshops and seminars are widely-used forms of doctoral training. However, research with a particular focus on these forms of doctoral training is sporadic in the literature. There is little, if any, such research concerning the international context and participants' own voices. Mindful of these lacunae in the literature, we write the current paper as a group of participants in one of a series of doctoral forums co-organised annually by Beijing Normal University, China and Queensland University of Technology, Australia. The paper voices our own experiences of participation in the doctoral forum. Data were drawn from reflections, journals, and group discussions of all 12 student and academic participants. These qualitative data were organised and analysed through Bourdieu's notions of capital and field. Findings indicate that the doctoral forum created enabling and challenging social fields where participants accrued and exchanged various forms of capital and negotiated transient and complex power relations. In this respect, the sociological framework used provides a distinctive theoretical tool to conceptualise and analyse the benefits and tensions of participation in the doctoral forum. Knowledge built and lessons learned through our paper will provide implications and recommendations for future planning of, and participation in, the doctoral forum series and similar activities elsewhere.

Keywords: International doctoral forum, Bourdieu, capital, field, power relations, autobiography

\section{Introduction}

Internationalisation has become a core dimension of the strategic vision of many universities throughout the world. This strategy enables the cross-boundary mobility of scholars that drives the expansion of global academic connections (Niu, 2013). Such connections boost knowledge exchange and social interaction among scholars and, consequently, contribute to the growing research productivity of universities (Adams, Black, Clemmons, \& Stephan, 2005; R. B. Freeman, 2010; Kalaitzidakis, Mamuneas, Savvides, \& Stengos, 2004). As such, promoting scholar mobility is becoming increasingly visible in universities' internationalisation initiatives (Brookes \& Becket, 2011; Leask, 2007; Lunn, 2008; Spencer-Oatey, 2013; Stohl, 2007). In addition to scholar mobility, internationalisation in higher education has also seen growing quantity and quality of student exchange across the country borders. Despite a growing emphasis on nurturing undergraduate and postgraduate coursework students into "global graduates" (Spencer-Oatey, 2013, p. 245), limited attention has been paid to promoting international connectivity among research students, especially doctoral candidates who are emergent scholars in the academia (Pfotenhauer, Jacobs, Pertuze, Newman, \& Roos, 2013; Teichler, 2004). The current paper wades into this void by interrogating our experiences as participants in one of a series of doctoral forums that facilitate learning and networking of doctoral students from Beijing Normal University (BNU), China, and Queensland University of Technology (QUT), Australia.

Our study aims to examine the benefits and challenges of participating in the 2013 Doctoral Forum (hereafter as 'the 2013 Forum'), and to provide implications for future doctoral forums of the series and similar international academic activities elsewhere. To this end, we organise our paper in six parts. First, we set the scene of our paper by providing a succinct introduction to the doctoral forum series. Second, in a short literature review, we synthesise the limited empirical work that has explored doctoral workshops or seminars. Third, different from the bulk of extant higher education literature, we adopt a sociological theoretical lens, using Bourdieu to conceptualise dynamic social spaces constructed through the 2013 Forum that nurtures and troubles scholarly and cultural learning. Fourth, we explain our methods for data collection through multiple sources reflections, journals, and group discussions. Next, we report on data analysis through a deductive approach (Boyatzis, 1998; Braun \& Clarke, 2006), informed by Bourdieu's sociological notions of capital and field. Finally, we conclude our paper with some recommendations, which we hope 
are useful not only for our future doctoral forums but also for doctoral learning and training elsewhere.

\section{Background}

Our annual doctoral forum series is built upon the long-term cooperation between BNU and QUT. The partnership between the two universities dates back to the early 1990s when Education Faculty members specialising in early childhood education and educational psychology began academic and research collaboration. Since then, numerous academic exchange programs, both long term and short term, involving students, academics, and senior leaders, have occurred. These bilateral collaborations between the two universities seem no different from those elsewhere. However, one aspect of the partnership, that is, the continuous commitment to developing the annual doctoral forum series, is noteworthy. This commitment was formalised by the Memorandum of Understanding (MOU) signed in 2007 and renewed in 2009. The commitment strongly aligns with the strategic plans of both universities (e.g., Beijing Normal University, 2015; Queensland University of Technology, 2014), stressing the internationalisation of postgraduate programs that extends research students' international experience and promotes the sustainable development of bilateral research collaborations.

The annual doctoral forum contains a one-week program hosted by each university in alternate years. The forum provides a resourceful opportunity for doctoral students from the two Faculties of Education to work with, and learn from, international peers. This forum series is facilitative of the continuous growth of the academic network because each year a different group of doctoral students is invited to participate. Conventional activities of the forum include academic seminars, student presentations, school visits, and cultural tours. An academic writing workshop has become a key component of recent doctoral forums, with the objective of nurturing co-publications among forum participants. This paper, similar to the ones published from previous forums (e.g., Li, Fox, \& Davis, 2013; Mu \& Jia, 2014; Mu et al., 2013), is an outcome of the collaborative learning and research of the 12 participants in the 2013 Forum. Figure 1 and the following vignette contain pictures and information to provide a snapshot of the 2013 Forum.

\section{A vignette}

The 2013 Forum constructed multilayered and inter-nested learning spaces across the psychical, social, and cultural dimensions. The intensive one-week program provided us unique opportunities to engage with in-depth scholarly discussions, present our research, attend guest lectures, visit local schools, organise academic writing workshops, eat together, and tour around Beijing (see Figure 1). On one particular day, we were generating and sharing ideas about how to write from the forum collaboratively. Coming from different cultural backgrounds, educational fields, and methodological traditions made this task challenging but invigorating. How could we merge our various interests and skill sets to do collaborative research and writing together? On a subsequent day, the group explored ways to theorise the forum, including using a Bourdieusian lens which then became the theoretical focus of this paper. 


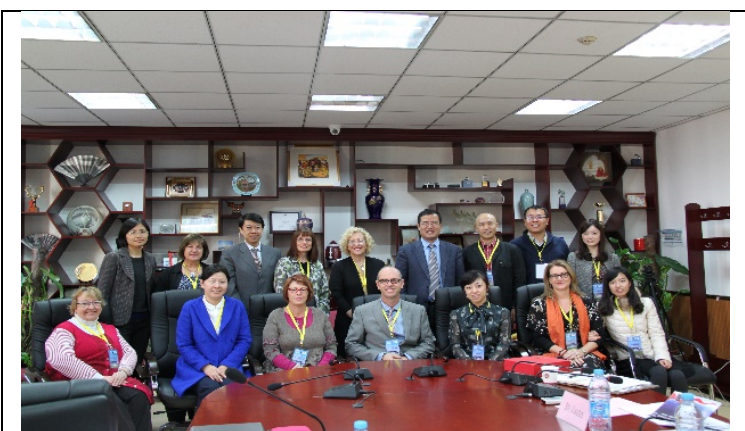

Official event

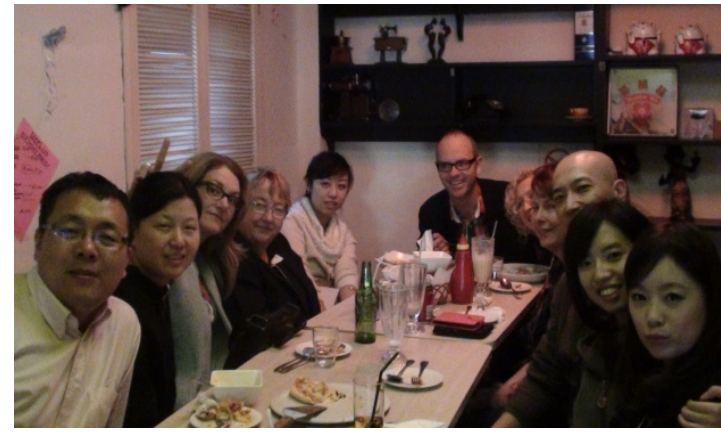

Dinner time

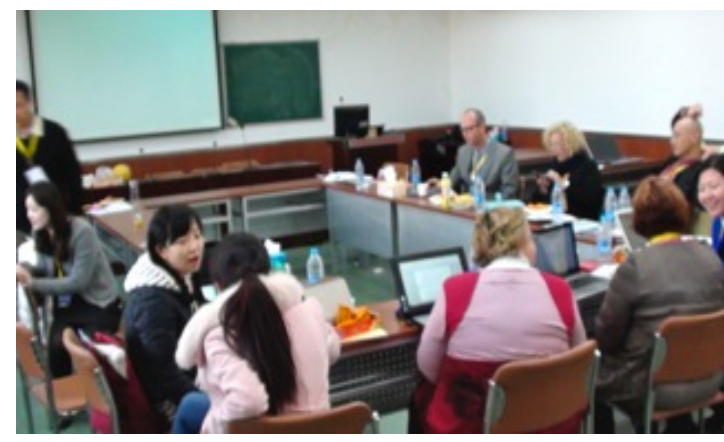

Writing together

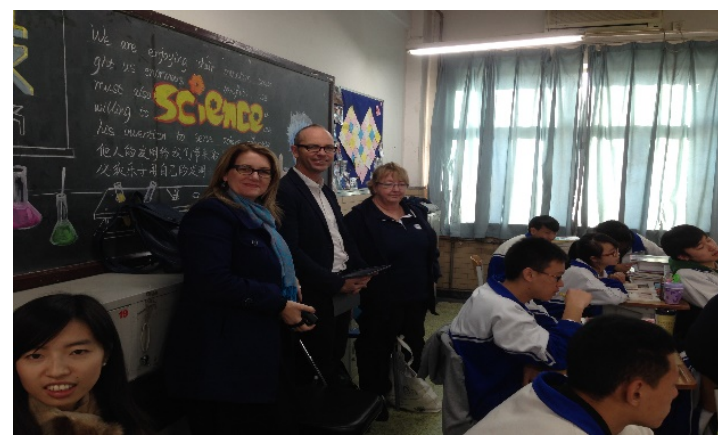

School visit

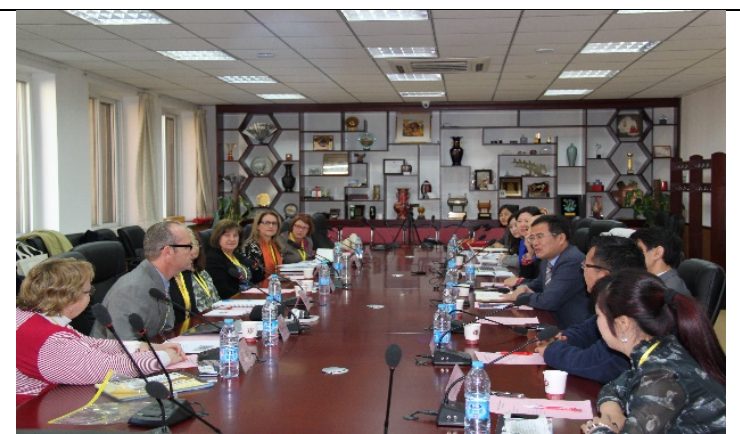

Group discussion of future work

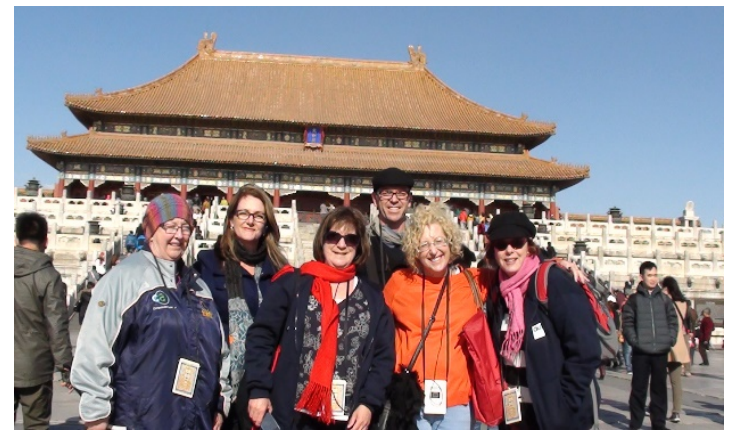

Cultural tour

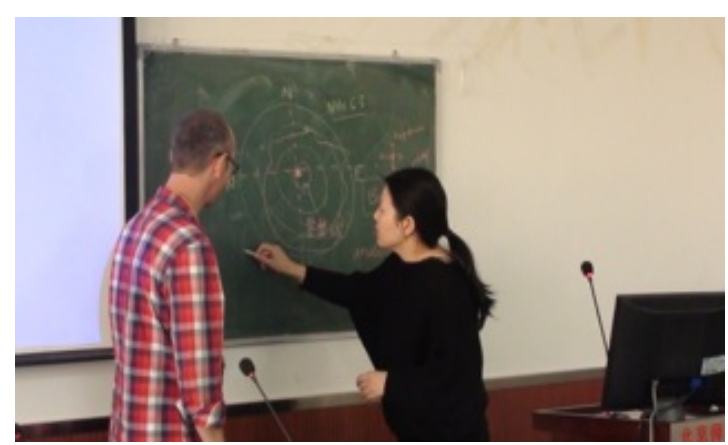

Peer collaboration

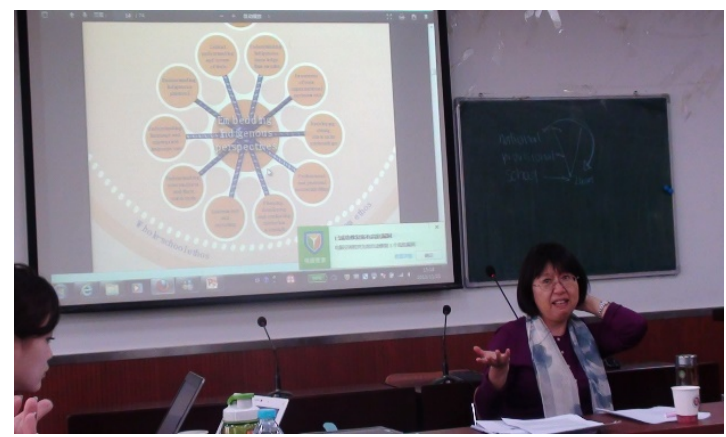

Guest talk

Figure 1. The 2013 Forum

We use the term 'forum' to take account of diverse activities included and various spaces constructed, and to differ from workshops or seminars that often have focused contents and objec- 
tives as well as fixed venues. Before investigating our experiences of participation in the 2013 Forum, we review extant knowledge about doctoral workshops and seminars documented in the literature.

\section{Literature Review}

This review generally examines literature about doctoral workshops, where doctoral students actively engage in learning through activities, discussions, and seminars, and where doctoral students may be provided with relevant scholarly information. We look at the structures of these learning modes and their benefits to doctoral students. This helps us identify the gaps in this body of literature.

\section{Structures and Benefits}

Extant literature has documented that doctoral workshops and seminars, in their various forms, structure a learning and thinking community for their participants. Workshops and seminars are widely-used forms of doctoral training and they take various forms, physical or virtual, local or international, one-off or ongoing. Workshop and seminar topics can range widely across enrolment decisions, program choices, scholarly learning, professional development, career planning, practical training, and cultural capacity building. With the proliferation of doctoral workshops and seminars, there emerge their clear goals, such as professional and social integration, working and learning in collaborative teams, enhancing scholarly knowledge through structured inquiry and intensive research activities, and building upon extant objectives (Zhao, Bentley, Reames, \& Reed, 2002).

The benefits of doctoral workshops and seminars are documented in the literature. For example, prior to the commencement of the doctoral program, introductory seminars, on- and off-campus as well as virtual, evidently help assess program ethos and personal compatibility, in addition to informing, inspiring, and persuading potential doctoral students (Kanyi, 2009). Highly interactive workshops in the initial stage of doctoral study encourage academic debate and doctoral development (McVicar, Caan, Hillier, \& Munn-Giddings, 2006). Specifically, such workshops can expand doctoral candidates' horizons in respect of methodologies and provide a breadth of awareness and preparation for leadership within an interdisciplinary environment. Though not specific to doctoral workshops, similar findings were reported elsewhere (e.g., Leiper, Horn, Hu, \& Upadhyaya, 2008). Additionally, doctoral seminar participants have reportedly enhanced their scholarly learning by risk taking, working together, and reflection (Henderson et al., 2008). Findings from the study of Dinkelman et al. (2012) indicated that a doctoral seminar for future teacher educators help participants map the terrain of their research, prompt the topic of their research, learn a language for teacher education, value collaboration, and define purpose and care for the practice of teacher education. This was largely echoed by the study of Vescio, Bondy, and Poekert (2009) on a doctoral seminar for future teacher educators. Through its attempts to foster seminar participants' multicultural knowledge, sociocultural dispositions, and active exploration of the current education system, the seminar helped to cultivate culturally competent educators responsive to increasingly diverse societies. Likewise, a study by Falls, Jara, and Sever (2009) showed how an experiential workshop enabled current educational leadership doctoral students to change, and unveiled students' emotional sources of resistances to change by reflecting on their reactions. Workshop participants were more likely than didactically taught educational leadership students to draw on experience to inform their choices regarding management of change processes in their future educational leadership positions.

Apart from the aforementioned forms and benefits, virtual doctoral engagement often helps to break the boundaries of time and space. At the temporal level, asynchronous communication in online doctoral forums has been considered by doctoral students as a collaborative, constructivist 
learning process (Abramson, 1999). Consequently, forum participants have seen the value of continuing contribution to the online doctoral forum. At the spatial level, online doctoral seminars are not constrained by geography, and hence are able to bring together doctoral students from different institutions and countries. Teng, Chen, Kinshuk, and Leo (2012) reported a novel design of an online synchronous seminar for doctoral students across Canada, Italy, New Zealand, and Taiwan. The effective instructional design and facilitation of the online seminar were found to promote interactions among learners, instructors, and the content, and helped to build a learning community. In addition, virtual engagement overcomes the barriers of international travel. Despite these attributes, virtual seminars would not provide participants with opportunities to gain cultural and social benefits and to negotiate tensions through face-to-face interactions, like the one reported in the current paper.

\section{Gaps in the Literature}

Existing knowledge, though limited, has pointed to the methodological, professional, and cultural benefits of doctoral workshops. However, the particular challenges emerging from such workshops are largely undocumented. There is also a dearth of studies drawing insight from participants' first-hand perspectives to unearth their socialisation patterns and dynamics that are facilitative of learning. Moreover, most previous work about doctoral workshops has been descriptive in nature. Conceptualisation and theorisation of such workshops are scarce in the literature. Limited examples can be enumerated here. Austin (2009) uses the cognitive apprenticeship theory (Collins, Brown, \& Holum, 1991) to understand how doctoral seminars enable lecturers to provide first-year doctoral students with more focused scaffolding and explicit feedback, as well as more systematic and enhanced preparation for collaborative learning within communities of scholars. Other colleagues (Bentley, Zhao, Reames, \& Reed, 2004; Zhao et al., 2002) use the four leadership frames (political, structural, human resource, and symbolic) of Bolman and Deal (1993) to conceptualise the cohort-based doctoral learning. To our knowledge, there is scant sociological examination of the nature and dynamics behind the benefits and challenges emerging from doctoral workshops.

The doctoral forum examined in this paper differs from those reported in the literature in numerous ways, including: (a) its durability over the past years; (b) its transferability across the national borders of China and Australia; (c) its aim to develop sustainable academic networks amongst the forum participants; and (d) most importantly, its recent commitment to joint publications by the forum participants. The last point is crucial because co-authored papers are perhaps the most visible items produced through academic exchanges. The current paper is produced through the ongoing collaborative work of all participants in the 2013 Forum. As indicated in the vignette, participants realised the usefulness of Bourdieu's sociology when discussing how to theorise the Forum. Therefore, we use Bourdieu's sociology to move beyond existing higher education discourses that tend to focus extensively on the qualities of doctoral education. To help frame our investigation and underpin our data analysis, we now briefly visit Bourdieu's key notions of capital and field.

\section{Theoretical Framework: A Bourdieusian Perspective on the Doctoral Forum}

In light of Bourdieu's sociology, participants in the 2013 Forum are considered as learners who possess different quantity, quality, and forms of assets, and expect to access and acquire a wider range of resources as a return on their investment of time and effort in participating in the forum. At the same time, these participants come into various social spaces constructed through the Forum. They may have to constantly negotiate their positioning and position taking (Bourdieu, 1996) within these social spaces by virtue of the recognised value of the assets that they have. 
The relative value of these recognised resources and assets within certain social spaces can be conceptualised through Bourdieu's key sociological notions of capital and field.

Capital denotes a set of valued and recognised resources, with "a potential capacity to produce profits and to reproduce itself in identical or expanded form" (Bourdieu, 1986, pp. 241-242). According to Bourdieu (1986), capital has four convertible forms: economic, cultural, social, and symbolic. 'Economic capital' refers to forms of financial wealth, which can be "immediately and directly convertible into money and may be institutionalised in the form of property rights" and other material objects (Bourdieu, 1986, p. 243). 'Cultural capital' exists in three different states: valued cultural property and goods - "the objectified state"; legitimate knowledge, behaviour, and modes of thought - "the embodied state"; and institutionally recognised capacity, credentials, and qualifications that characterise different classes and groups in relation to specific sets of social forms - "the institutionalised state" (Bourdieu, 1986, p. 243). 'Social capital' is the aggregate of the actual or potential resources that accrue to an individual or a group by virtue of the possession of a durable network of more or less institutionalised relationships of mutual acquaintance and recognition, such as family, friends, clubs, schools, communities, and society (Bourdieu, 1986; Bourdieu \& Wacquant, 1992). 'Symbolic capital' refers to "a reputation for competence and an image of respectability and honourability" (Bourdieu, 1984, p. 291). It is known and recognised to be "more or less synonymous with: standing, good name, honour, fame, prestige, and reputation" (Bourdieu, 1993, p. 37).

The aforementioned forms of capital present themselves as rare and desirable in a particular social relationship located within a system of exchange, or a 'field' in Bourdieu's term. Hence, the concept of field is central to understanding Bourdieu's uses of capital in that capital does not exist and cannot function except in relation to a field (Bourdieu \& Wacquant, 1992). To clarify, a field is a structured social space of forces where "constant, permanent relationships of inequality operate" (Bourdieu, 2011, p. 40). It contains people who dominate and who are dominated. The position of these people is shaped by the relative power that they bring to the competition within a certain field (Bourdieu, 2011). This power is dependent on the quantity and quality of capital that people can obtain. In other words, capital gives power to people, which enables entry to, and position in, a particular field. At the same time, capital exists and generates itself in the field where it is produced and reproduced (Bourdieu, 1984).

In theoretical terms, as a return on their participation in the 2013 Forum, participants may gain different forms of capital; at the same time, according to the quantity and quality of capital at their disposal, participants may take different positions within various social fields constructed through the Forum. In this respect, we investigated two questions: (1) How did the 2013 Forum give participants access to previously unattainable resources? (2) How were the relationships between these participants formulated and negotiated over the period of the Forum? The structural and contextual scrutiny of these questions helps us to take stock of the sociological nuances and dynamics embedded within the Forum, to excavate how the learning through the Forum was performed and enabled, to conceptualise the benefits and challenges emerging through the Forum, and ultimately to make a contribution to doctoral learning and training.

\section{Method}

In the two months prior to the Forum, this qualitative, autobiographical study (Bullough \& Pinnegar, 2001) was initiated and conceptualised, and ethical clearance for low risk human research was gained. The Forum participants, also the authors of the current paper, included five BNU and four QUT doctoral students, one BNU and two QUT academics, forming a total of 12 participants (three men and nine women). The student participants were chosen from a competitive application process. Table 1 briefly describes the 12 participants. 
Table 1. Participant information

\begin{tabular}{|l|l|l|l|l|l|}
\hline Name & Age range & Gender & Role in forum & Research field & First language \\
\hline Charles & $30-40$ & M & Student & Education technology & Chinese \\
\hline Hilary & $60+$ & F & Mentor & $\begin{array}{l}\text { International students' in- } \\
\text { formation experience }\end{array}$ & English \\
\hline Jennie & $40-50$ & F & Student & Inclusivity & English \\
\hline Jennifer & $40-50$ & F & Student & Literacy education & English \\
\hline Jennings & $30-40$ & F & Student & School leadership & Chinese \\
\hline Jillian & $40-50$ & F & $\begin{array}{l}\text { Mentor/ } \\
\text { Coordinator }\end{array}$ & Early years mathematics & English \\
\hline Joey & $30-40$ & F & Student & Higher education & Chinese \\
\hline Lyn & $50-60$ & F & Student & $\begin{array}{l}\text { Standardised testing in } \\
\text { school numeracy }\end{array}$ & English \\
\hline Matt & $40-50$ & M & Student & Industry-school partnerships & English \\
\hline Michael & $30-40$ & M & $\begin{array}{l}\text { Mentor/ } \\
\text { Coordinator }\end{array}$ & Diversity and inclusivity & Chinese \\
\hline Mu-chu & $20-30$ & F & Student & Chinese education history & Chinese \\
\hline Xiao-Bo & $20-30$ & F & Student & Early childhood & Chinese \\
\hline
\end{tabular}

Prior to the Forum, each student participant wrote an initial reflection with respect to the expectations of the forthcoming event. During the Forum, participants individually and collaboratively wrote reflections on meaningful and powerful learning moments experienced. In total, there were nine, individual, pre-forum reflections written by the nine doctoral students, and 24 on-site reflections, which formed our database. Of all these reflections, two were generated collaboratively through on-site oral discussions, with notes audio-recorded in real time.

To allow consistency in data collection and analysis, the participants all used the $5 \mathrm{Rs}$ Model (Bain, Ballantyne, Mills, \& Lester, 2002) to structure their reflections. The 5Rs Model offers a systematic process through which the writer gradually deepens their understanding about the nature and implications of a particular critical incident, through the 5 stages of: Reporting, Responding, Relating, Reasoning and Reconstructing. This approach enables the opening of mental space and the recall of past activities and situations. As a result, the use of the $5 R s$ Model provided us an opportunity to offer rich collective and individual insights about the entire forum. Importantly also, this approach allowed us to identify lessons and advice for future forums and doctoral learning and training in general.

Reflection data were analysed immediately after the Forum, using a deductive approach (Boyatzis, 1998; Braun \& Clarke, 2006) informed by Bourdieu's notions of capital and field. The data were analysed in a recursive way. The qualitative data analysis software NVivo was used. The BNU group and the QUT group firstly examined the reflections separately but concurrently, and then exchanged the analytical results for further investigation by the counterpart group. The final analysis stage included frequent email interactions between the two groups. This stage enabled the comparison of the analyses conducted separately by the BNU group and the QUT group. Ambiguities were clarified and differences were discussed. A combination of predetermined, theoretically informed, and emerging themes was generated.

The analytical process ended up with a coherent view of the patterns in the data. Meanings embedded in the reflections emerged through interpretation and reinterpretation, negotiation and re- 
negotiation, as well as construction and reconstruction. In this vein, knowledge produced through the analysis was systematically crosschecked and mutually verified. This analytical process offset the limitation of autobiographical research; "the centrality of the researcher self" (Bullough \& Pinnegar, 2001, p. 15) since common agreement was reached through reciprocal critique and communicative validation among the co-authors. Through this active process of witnessing, reflecting, and examining our own experience, we engaged in purposeful learning and uncovered new knowledge.

One limitation of this study was the small number of participants from which data were gathered: 12 and only nine of these were doctoral students. This makes generalisability unlikely although other similar students may find the findings and discussion applicable to their situations (Simons, 2009). The difficulties associated with the BNU students writing in an additional language, English, could also be seen as problematic. However, this was part of the aim of the Forum and was factored into the analysis process and the time allocated for it. While proficient in English for many purposes, the BNU students required assistance with making their meaning clear in emails and in writing clearly for publication in English. The BNU academic, highly proficient in both Chinese and English, was able to mediate meaning-making between the two groups until clarity was reached.

\section{Findings}

The 2013 Forum constituted multilayered, inter-nested social sites of academic exchanges and cultural experiences. Each site can be conceptualised as "a structured social space" or a "field" in Bourdieu's (2011, p. 40) term. Participants of the Forum came to these linguistically constituted and interpersonally negotiated social fields with different dispositions and positions and, therefore, learned to gain previously unattainable forms of capital. These social practices within different fields came to shape the relationships between participants. How the Forum participants accessed previously unattainable resources and how they negotiated the tensions over the period of the Forum were analysed in order to give answers to the two research questions that we posed earlier.

The participants' initial reflections show that they variously expected to establish or strengthen "friendships", to develop research "partnerships", to learn or improve the language spoken by their counterparts, to gain contextual knowledge about Chinese and Australian education, to broaden their scholarly horizons, and to jointly produce a paper. In their on-site reflections, participants wrote of perceptions, experiences, and lessons gained through the Forum. The findings are reported and organised according to Bourdieu's theorisation of capital and power relations in fields.

\section{Production of Cultural Capital}

Many participants reported obtaining appropriate cultural resources and assets in various forms at different times and places throughout the entire life of the Forum. Bourdieu's conceptualisation of cultural capital in objectified, embodied, and institutionalised states all emerged from our data, as outlined in turn below.

\section{Embodied cultural capital}

The generation of culturally appropriate inclinations and behavioural patterns was repeatedly mentioned in participants' reflections. These dispositions of mind and body, acting in a way that shows culturally appropriate manners and competences, are what Bourdieu meant by cultural capital in its embodied state (Bourdieu, 1986). 
Some QUT participants were aware of their BNU partners' culturally "formal and hierarchical" approach to the Forum, which "was most evident during the opening ceremony". As one QUT participant noted, "the opening ceremony consisted of cultural protocols ... When he [the Dean of the hosting education faculty] stood, we all stood." Similarly, another QUT participant started to understand the culturally appropriate way to make a toast at a formal Chinese dinner. She wrote in her reflection: "We now know that 'Gombye' ['bottoms up' in English] isn't for every occasion, just as in Australia there are social nuances between 'good health', 'cheers', and 'bottoms up'.” Interestingly, some QUT participants have noticed their BNU peers' inclination to adopt Australian ways of doing things. For example, one of them noticed that a BNU participant had become more accustomed to Australian tendency to greet friends with a hug: "I now hug [him] and he doesn't pull away. He had to get to know what this meant."

These participants have reportedly learned to follow the appropriate cultural rules and interest, and therefore formulated the culturally legitimated "schemata of perception and action" (Bourdieu, 1996, p. 5). In some BNU participants' words, they gained "the power of having knowledge of other people's cultural norms and values in order to foster empathy and respect" and they recognised "respecting and understanding different cultures" as "the most important thing" to close the gaps between "the Chinese culture and the western culture". In theoretical terms, these learned forms of embodied cultural capital included the know-how capacity when moving across different social spaces (Bourdieu, 1991). Nevertheless, the accumulation of embodied cultural capital demands a process of embodiment and incorporation, and a labour of inculcation and assimilation (Bourdieu, 1986). This was evident in one QUT participant's reflection: "I'm probably going to annoy the Chinese students by asking too many questions about their culture."

In our data, production of embodied cultural capital was not limited to the cultural realm but sometimes expanded to the obtainment of valued linguistic and scholarly knowledge. A BNU participant commented:

I learned how to find a journal [published in English], and how to compose a paper [in English], and how to arrange the data, etc. ... I believe the doctoral forum is a good chance for learning English language and ... different ideas ... and the Australian culture.

In addition, participants tended to link the learned scholarly knowledge to their own academic area. "Similarities" and "differences" between China and Australia in their researched area were repeatedly reported in participants' reflections. For example, after observing an English lesson in a local school, a QUT participant, who researches second language English teaching, reflected:

I was familiar with the topic-based, textbook-based syllabus and the teacher-centred approach [in China] ... This way of teaching English is so different to how it is taught in Australia. We have whole class discussion. We don't use text books. We don't focus on reading comprehension alone but on higher order thinking as well, such as critical literacy. It's no wonder our Chinese [international] students sit mute in our English classes. It is so alien to them.

Likewise, another QUT participant, who made a professional connection with a BNU scholar during the Forum, wrote:

This serendipitous linking with [name of the BNU scholar] has enabled me to gain deeper understanding about the previous library experiences of Chinese students who I work with in Australia. This gives me a more informed basis for research and pedagogy in our culturally diverse higher education context. 
These participants captured useful scholarly knowledge immediately transferable to their own research field. In this respect, participation in the Forum helped them produce embodied cultural capital.

\section{Objectified and institutionalised cultural capital}

Some participants also spoke of benefits that can be conceptualised through Bourdieu's notion of capital in objectified state. For example, "sufficient reading materials could offer background knowledge to participants", as indicated by a BNU participant. These reading materials can be conceptualised as objectified cultural capital that usually appears in the material form of concretely displayed cultural goods (Bourdieu, 1986). In addition, some participants talked about the "high value" placed on the partnership between BNU and QUT. This partnership has been formalised through a collaborative MOU, or the institutionalised cultural capital that exists as an institutionally recognised connection to certain organisations and confers on its holder a conventional, constant, legally guaranteed value with respect to cultural resources (Bourdieu, 1986).

Furthermore, some participants strategically aimed to co-author papers that might evolve as outcomes of participation in the Forum, the current paper included. For example, one QUT participant wrote, "Hopefully we will get a lot of planning, data collecting and writing done on our joint paper. This is a golden opportunity to write with the team while we are all together." Similarly, a BNU participant noted, "I'll like to find Prof [name]'s work published in English and to seek ways to write a comparative education paper." These papers, when produced, will become concretely displayed cultural goods, and when published, will become institutionally recognised connection to certain journals and publishers. In this vein, these papers, including the current one, can be understood as cultural capital in its objectified and institutionalised states.

\section{Production of Social Capital}

Gaining institutionalised research connections and friendships were reportedly other benefits produced through the participation in the Forum. This is evident in one QUT participant's comment that "in every reflection I see: relationship, friendship, partnerships" as well as in her reflection, "we soon established a friendly rapport on a personal and professional level". At the professional level, participants reported that "the discipline-specific connections occurred naturally through conversations between the Chinese and Australian students". At the personal level, participants regarded the formation of "positive and warm feelings" as "additional benefits emerging from the workshop - benefits beyond the academic level". "True friendship", "trust", "care", and "love" were some common terms used in the reflections. A QUT participant wrote: "It struck me that we had quickly established a rapport and a strong group dynamic which was supportive and empathetic. It felt unbelievable that we had so quickly made friendships."

Friendship became a strong common theme in our data due perhaps in part to an accident that caused a serious injury to one QUT participant. In face of this incident, everyone else worried, cared, and helped. The wounded participant wrote in her reflection:

With regard to my stair falling incident, despite the discomfort and frustration for me, and inconvenience to other forum participants, I feel it again highlights how privileged we are to be part of the doctoral forum at BNU. To be treated with such genuine care by our hosts seems to show that genuine human connection, beyond formal pleasantries, which underpins our partnership.

These "partnerships", "connections", and "friendships" could be interpreted as social capital in Bourdieu's term. It was constituted through the accumulation of "contacts and group memberships", "exchanges" and "shared identities" (Bourdieu, 1993, p. 143). In addition, social capital 
can "provide actual or potential support and access to valued resources" (Bourdieu, 1993, p. 143). For example, before leaving for China a QUT participant wrote of her QUT Forum peers:

They all seem like congenial travel and study buddies. I hope we'll all be OK with each other. The developing rapport among the members is promising sign that we'll be able draw on each in managing any challenges and gaining the best from this shared adventure ...We also identified common ground in our research interests ...We agreed to pursue collaborative research together.

"Managing any challenges", "gaining the best", and "to pursue collaborative research" can be understood as "potential support and access to valued resources" by virtue of the accumulation of social capital. In contrast, the efficient management of the accident can be an example of the "actual" profits brought by social capital. When the accident occurred, the Education Dean of BNU called "his influential contact, the Director of a nearby hospital", the wounded participant recalled. Later she wrote in her reflection:

At the hospital, I was taken straight into the emergency department, without any interminable waiting ... I was realising that I probably wouldn't get out of this situation alone. This proved to be the case, and thank goodness there were so many caring people around who allowed me to rely on them to get me fixed.

\section{Production of Symbolic Capital}

Symbolic capital was also reportedly produced through the Forum. One of the ultimate goals of the 2013 Forum, like the previous one, was to produce a joint paper - a recognised outcome of scholarship in academia. Consider a comment in a reflection of a BNU participant: "Publications will help to build the professional identity and scholarly prestige of the writers. The copublication will be a powerful symbolic outcome of the long-term cooperation between the two universities." These publications can be seen to represent "prestige" and "symbolic outcome" as examples of Bourdieu's symbolic capital. The manifestations of this capital include accumulated resources and various key markers of standing that are founded on the recognition granted by others and perceived as legitimate (Bourdieu, 1985, 1991).

Take the following excerpt as another example: "The opening ceremony consisted of cultural protocols where the Education Dean was afforded seniority and honour ... It was very important to honour the right people according to their standing within their respective university." For one more example, one QUT participant felt that her talk to some Chinese undergraduate students was "well received". She felt honoured when the audience thought highly of her talk. In the two examples mentioned above, the "standing" of the Dean cannot accrue symbolic capital without being "afforded seniority and honour" by the Forum participants. Likewise, the QUT participant cannot gain symbolic capital without being "received" by the Chinese undergraduate students. This highlights the nature of symbolic capital - recognition by others.

\section{Investment of Economic Capital}

Economic capital is the most effective (Bourdieu, 1986), but the least discussed, capital form in the Bourdieusian school due to Bourdieu's focus on cultural resources in his sociology instead of material resources as highlighted by other schools like Marxism. Production of economic capital was the least evident capital in our data. Despite the lack of evidence that economic capital was produced through the Forum, some participants spoke of the institutional investment of economic capital. One BNU participant briefly mentioned the financial support that participants received from their universities. He wrote in his reflection: "The universities pay us to participate in the workshops. We feel obliged to reward our universities. We will keep working on publications in the prospective workshops." 
The above quote recognises the institutional investment of economic capital that financially supported the current and previous doctoral forums. This capital is at the root of all other forms of capital given its potential capacity to produce profits in expanded forms (Bourdieu, 1986). As evident in our data, any of the following can be understood as returns on the institutional investment of economic capital. Publications emerging from the Forum are a form of symbolic capital valued in academic fields; knowledge gained through the Forum is a form of embodied cultural capital; and any networks built by virtue of the Forum are a form of social capital. Although only minimally evident in our data, it is arguable that the economic investment by the universities has the potential capacity to be converted into other forms of capital analysed above. In other words, economic capital had an important impact, behind the scenes, by providing Forum participants with the resources to build and fund other capital forms.

\section{Power Relations}

One of the challenges of the 2013 Forum was that participants had to constantly negotiate power relations in various situations, willingly or unwillingly. The following analysis delves into the power relations contextualised in the international context of the Forum, which is forcibly visible in our data. As a QUT participant noted in her reflection, "I was also very conscious of the power relations during our interactions ... I think that when working in other countries, we must be aware of the power positions we take." The emergence of power relations can be largely attributed to the international feature of the Forum, where different cultural and linguistic backgrounds of the participants came into play. In this vein, the Forum has become "a field of forces", where "relationships of inequality operate" (Bourdieu, 2011, p. 40).

Language, a particular form of embodied cultural capital, can engender authority in social situations and act in a way that shows privilege or advantage (Bourdieu, 1986). The particular language used in a given situation can prioritise certain people who are proficient in this language but marginalise others who are not. This makes sense in social fields where there are people who dominate and who are dominated because of the relative value associated with the linguistic capital at their disposal at different times and places (Bourdieu, 2011).

During the Forum, the BNU participants reportedly felt that the use of English as the Forum's working language was "mentally taxing" because for them it is a foreign language. Consider an excerpt from the reflection of a BNU participant:

The Australian students seem more open and would like to express themselves, but the Chinese students tend to listen more than speaking out. I think part of the reason is the language. English is not our mother language. So sometimes it is a bit difficult for us to express clearly what we would like to say.

Consequently, the BNU participants were not as responsive or active as their Australian peers. A QUT participant observed: "The students coming from BNU seem to be much shyer to speak out what they were feeling."

In these situations, there was a definite asymmetry of power, consciously or unconsciously, during the academic communications between the Chinese and the Australian participants. This is significant because within the linguistic field of the Forum in particular, or any international conference in general, English is one of the most commonly used languages. In other words, use of English is a rule in these linguistic fields. Chinese participants, speaking English as a foreign language, were in a disadvantaged position in a hierarchy established through the level of proficiency in the legitimate language. To enter a field requires capital and capital in turn enables positions in a field (Bourdieu, 1986). It was the lack of this particular form of embodied cultural capital that sometimes excluded the BNU participants from the academic conversation. Similar challenge brought by communicating in English was also reported elsewhere when a group of international 
doctoral students participated in an online doctoral community (Dahlgren, Grosjean, Lee, \& Nyström, 2012).

Interestingly, power relations between participants were not immutable. Instead, the positioning was shifting, constantly constructed and reconstructed, and contingent on the logic, interest, or "rules" (Bourdieu \& Wacquant, 1992, p. 117) of a specific field. In situations where Chinese language carries legitimate value, the Australian participants reportedly became vulnerable. Consider the following excerpts:

During most previous travels my knowledge of several European languages has enabled me to manage personal interactions and daily routines fairly easily and independently. But this time, as I have no knowledge of Chinese beyond 'nihou' [hello] and 'tsie tsie' [thank you], I shall be largely dependent on others.

On arrival in hospital I became acutely aware of the vulnerability of being linguistically inept, unable to communicate my concerns or needs to the doctors I relied on to make me better. This was a confronting new situation for me as an international boundary crosser.

It is evident in our data that the quantity, quality, and forms of capital within particular social fields constructed through the Forum come to shape certain power relations between Forum participants who are dominant and those who are subordinate. The participants sometimes were conscious of their social positions in a given situation, subordinate positions in particular, when participants failed to perform a culturally appropriate practice because of the lack of certain forms of embodied cultural capital. Returning to the example mentioned earlier, when the Education Dean of BNU proposed a toast to the continuing success of the doctoral forum series at a formal dinner, some QUT participants reportedly felt "surprised" that the Dean "emptied his wine glass with one gracious gulp". The QUT contingent then cheered "Gombye". When politely advised by the Chinese host that "Gombye" translates as "Bottoms up", some QUT participants reportedly realised that their cheers of "Gombye" were "not really appropriate in a formal social context". One QUT participant wrote in her reflection about the feeling of this particular moment: "Oops! I felt a moment of silent panic."

This feeling of "panic" can be understood as forms of bodily emotion, which, according to Bourdieu (2000, pp. 169-170), is "the practical recognition through which the dominated, often unwittingly, tacitly accept the limits imposed on them", "sometimes in internal conflict" that remains "with the violence of the censures inherent in the social structures". Bourdieu (2000) further explains that bodily emotion often takes the forms of shame, timidity, anxiety, guilt, blushing, inarticulacy, clumsiness, and trembling. In this example, there were indeed moments when participants demonstrated the feeling of inappropriateness or "panic". This is the bodily emotion of a dominated experience in a given field generated by the lack of a particular culturally appropriate response, a form of embodied cultural capital valued in this field.

\section{Discussion}

Our qualitative data evidently suggests that the Forum is a resourceful social field that enables capital accruement and exchange. At the same time, the Forum is also a challenging social field where power relations have to be constantly negotiated. In response to these findings, we discuss the Forum in four ways.

Firstly, the Forum was constitutive of various inter-dependent linguistic, cultural, social, and physical fields. The niceties and minutiae of the meaningful and powerful learning moments occurred within these diverse fields. Through the life of the Forum and the ongoing connections afterward, participants had the opportunities to experience, learn, and grow as a dynamic cohort 
of doctoral students, emergent researchers, social agents, and 'cultural persons' (Gasset, 1944). Participants reportedly obtained previously unobtainable forms of capital - cultural, social, and symbolic. Although the Forum does not accord with the conventional 'cohort-based model' (Bista \& Cox, 2014; Lei, Gorelick, Short, Smallwood, \& Wright-Porter, 2011) in definition, benefits emerging from the Forum strongly align with those produced through the cohort-based model. For example, learning within a cohort nurtures interpersonal development and personal attributes, fosters management and communication skills (S. Freeman \& Kochan, 2012), offers an integral part of personal and professional support for academic interactions (Nimer, 2009), and develops a shared learning community through a strong social and professional network (Hyatt \& Williams, 2011; Williams, Simpson, \& Cunningham, 2010). All of these can be understood as valued and recognised capital in its cultural and social forms within different fields created through the cohort-based learning. This points to the empirical and theoretical significance of our paper. At the empirical level, the 2013 Forum creates opportunities for "peer learning" - "a more appropriate pedagogic discourse" that facilitates doctoral education (Boud \& Lee, 2005, p. 501). At the theoretical level, our sociological perspective provides an opportunity to reframe and reconceptualise previous research.

Secondly, a characteristic feature of the Forum is its commitment to supporting co-publications by Forum participants. This commitment is highly consistent with internationalisation indicators related to shared output of both Chinese and Australian universities (see Higher Education Institute of Southwest Jiaotong University, 2013; Universities Australia, 2013). Literature also shows that the degree of openness of a research team towards other institutions and/or countries, the frequency of co-authorships, and the average size of co-authoring teams are important determinants for high-quality research productivity (Carilloa, Papagni, \& Sapio, 2013). Bibliometric literature indicates that the impact of the papers grows as the number of authors increases, especially when the authors are from multiple countries (Jeong, Choi, \& Kim, 2011; LanchoBarrantes, Guerrero-Bote, \& Moya-Anegón, 2013; Pečlin, Južnič, Blagus, Sajko, \& Stare, 2012). Specifically, bibliometric analysis has seen a dramatic increase in co-authorships between Chinese and Australian scholars, from just four co-authored papers in 1981 to 2,040 in 2010 (Niu, 2013). Through co-authoring, not only formal scholarly knowledge is exchanged but also a broad range of contextual information, micro-organisational capabilities, and social and technical skills is produced (Niu, 2013). Interestingly, the presence of doctoral students in a research team has been found to be one of the most effective factors for increasing the production of excellent publications (Carilloa et al., 2013). This intention underpinned the collaborative writing of the present paper by a relatively large group of doctoral students and academics from two different countries. As suggested by the literature, the paper, when published, will be a valuable element of exchange to strengthen relationships and to disseminate results from research discoveries. As such, the paper is a form of visible academic production (the objectified cultural capital), a form of recognised knowledge created by the Forum participants (the embodied cultural capital), a form of accreditation by the publishers and journals (the institutionalised cultural capital), and a form of asset full of value, honour, and pride (symbolic capital).

Thirdly, within various empowering social fields constructed through the Forum, participants have obtained intercultural competence and awareness, established collegiality and friendship, and developed intellectually stimulating collaborations. These outcomes echo the national initiatives of higher education of both China and Australia. International exchange and cooperation in Chinese education calls for Chinese universities to cultivate inter-culturally responsive and internationally resourceful intellectuals (State Council, 2010). Similarly, Australia's prosperity in the Asian century largely depends on the capacity of its universities to build 'Asia-relevant' capabilities, including encouraging university students to gain overseas experiences, particularly in Asia (Australian Government, 2012). Against this backdrop, the Forum has become an innovative program with an international orientation in its content and form, aimed at preparing forum partici- 
pants for performing scholarly, professionally, and socially in an international, cross-cultural context. Therefore, the Forum is a transforming and enabling instrument that contributes to the international knowledge base of both countries.

Lastly, the fundamental change in research culture has seen increasingly diverse doctoral students coming together in the push towards widening participation from different cultural and linguistic backgrounds (Lee \& Danby, 2012; Rizvi, 2010). This is particularly true for the Forum where participants from China and Australia had to negotiate the power relations and recast the heterogeneity and hierarchies into flexibility, multiplicity, and collegiality through a networked style of learning. In this way, the model of the Forum invites a rethinking of doctoral learning and training, through which doctoral scholars can cope with the changing research climate in a more responsive manner.

\section{Recommendations}

Through the process of working through our own reflections, we have developed the ability to understand our own perceptions, experiences, actions, and activities of the Forum. This process helps us to open up the possibilities and opportunities of purposeful learning, derived not only from the seminars and programs of the Forum, but also from our own words, voices, work, and lives. In our experience, close attention to cross-cultural and practical matters assists in establishing an environment conducive to sustainable doctoral partnerships. Based on the findings of this study, we offer the following recommendations for individuals and institutions. These recommendations will be useful for future doctoral forums and can also be applicable to other international workshops, seminars, or conferences.

At the individual level, to help facilitate discipline-specific connections, or to produce social capital in Bourdieu's term, participants could prepare in advance a research toolkit. The toolkit may include business cards, PowerPoint presentations, research interests, analytical tools and samples of previous publications. It would be beneficial to include a short session that provides participants with necessary contextual knowledge about the educational problems in each country and the opportunity to look at potential research collaborations. There is an evident need for mutual commitment to sensitively negotiating the cross-cultural tensions around the power relations brought by the language proficiency gap. Given the asymmetrical distribution of linguistic capital that exists in international workshops, all participants require extensive pre-forum support in preparing for this powerful cognitive exercise. During the forum, to enable second language speakers to fully participate, native language speakers have a responsibility to speak slowly and avoid complex terminology. On a practical note, the accident described earlier indicates the importance of being prepared for health emergencies. In particular, we advise participants to bring all pertinent medical details while travelling. Information, such as allergies and history of health conditions, could be life saving for the individual and lessen the stress for the leaders in an emergency situation.

At the institutional level, the success of the Forum, or probably any international workshops and seminars, is largely dependent on high levels of inter-departmental collaboration, organisational behaviour, and administrative guidance. The 2013 Forum is founded on the long-term, wellestablished, and ongoing partnership between BNU and QUT. This partnership has become a form of enabling, resourceful capital that facilitates the learning and socialisation within various, intermingled social fields constructed through the Forum. Hence, doctoral forums do not exist in a vacuum. Instead, they require systematic, enduring institutional support. 


\section{Conclusion}

In response to the two research questions, we have shown various ways in which the participants accessed previously unattainable resources and negotiated challenging power relations. The participants came to the Forum with various expectations - the enrichment of their scholarly knowledge and cultural understanding as well as the development of personal friendships and professional partnerships. As expected, they departed the Forum with various benefits. The quantity and quality of the produced benefits at given times and places were largely dependent upon the structures of different social spaces constructed through the Forum. At the same time, the Forum challenged these participants, constantly urging them to negotiate the transient power relations evolving from the unequally distributed cultural capital in different social fields. The positioning within these power relations was defined by the interest of different social fields that came to shape the value of different forms of capital brought by the participants to the Forum. In this respect, the benefits and challenges emerging from the Forum resonated with Bourdieu's theorisation of capital in fields.

At the micro level, the Forum has become an enabling and empowering social field where dynamic, interwoven social, cultural, and intellectual spaces are created. Within these rich and diverse social fields, participants bring various forms of capital at their disposal, which reflectively and responsively come to shape their negotiations around subtle, multilayered identities as doctoral students, emergent scholars, cultural learners, and normal persons. At the macro level, the Forum offers a diachronic opportunity for taking stock of the salience and immanence of higher education internationalisation. It has become an incubator to create emergent, confident scholars who are culturally capable and internationally resourceful to address important educational problems in China and Australia. Therefore, at both the micro and the macro levels, the Forum has constructed inter-nested and multilayered fields of dynamics and complexities. These fields bring up crisis moments that disrupt the "immediate fit between the subjective structures and the objective structures" (Bourdieu, 1977, pp. 168-169). That is to say, fields constructed through the Forum offer unique opportunities for participants to make sense of their own original dispositions and knoweldge, reflexively evaluate their gained cultural and scholarly capacities, and critically question their being, thinking, and doing in relation to the codes and grammars of the international contexts. Through negotiating emergent power relations within fields of domination and subordination, participants in the Forum bring " the undiscussed into discussion, the unformulated into formulation" (Bourdieu, 1977, p. 168). This is a sociological process of giving meaning to the previously unconscious dispositions - a phenomenon of 'habitus realisation' termed elsewhere (see Mu \& Dooley, 2015; Mu \& Strong, 2014).

The success of the Forum as a learning community has received attention from different parts of the world. A Canadian university will join the annual doctoral forum from 2015, broadening participation to three nations. A Japanese university has also indicated its interest in participation. The continuous growth of the network will see more complexities, diversities, and dynamics emerging from future doctoral forums. This will provide us with an unique opportunity to delve into questions like how to gauge the relative value carried by different forms of capital within the fields constructed through the doctoral forums, how to counteract the inequalities brought about by the power relations due to the unequally distributed capital, how the institutional habitus and capital come into play across the inter-nested and multilayered fields within the doctoral forums, and how we can share our learning within a wider community. 


\section{Acknowledgements}

The authors wish to sincerely thank our respective universities for the generous financial and academic support that enabled us to participate in this highly worthwhile international doctoral forum.

\section{References}

Abramson, T. (1999). Counting is not the solution. Journal of Instruction Delivery Systems, 13(4), 10-16.

Adams, J. D., Black, G. C., Clemmons, J. R., \& Stephan, P. E. (2005). Scientific teams and institutional collaborations: Evidence from U.S. universities, 1981-1999. Research Policy, 34(3), 259-285. doi:http://dx.doi.org/10.1016/j.respol.2005.01.014

Austin, A. E. (2009). Cognitive apprenticeship theory and its implications for doctoral education: A case example from a doctoral program in higher and adult education. International Journal for Academic Development, 14(3), 173-183.

Australian Government. (2012). Australia in the Asian century white paper. Canberra: Commonwealth of Australia.

Bain, J. D., Ballantyne, R., Mills, C., \& Lester, N. C. (2002). Reflecting on practice: Student teachers' perspectives. Flaxton, Qld: Post Pressed.

Beijing Normal University. (2015). BNU the 12th Five-Year Development Plan. Beijing: BNU.

Bentley, T., Zhao, F., Reames, E. H., \& Reed, C. (2004). Frames we live by: Metaphors for the cohort. Professional Educator, 26(2), 39-44.

Bista, K., \& Cox, D. W. (2014). Cohort-based doctoral programs: What we have learned over the last 18 years. International Journal of Doctoral Studies, 9, 1-20. Retrieved from http://ijds.org/Volume9/IJDSv9p001-020Bista0425.pdf

Bolman, L. G., \& Deal, T. E. (1993). The path to school leadership: A portable mentor. Thousand Oaks, CA: Corwin Press.

Boud, D., \& Lee, A. (2005). 'Peer learning' as pedagogic discourse for research education. Studies in Higher Education, 30(5), 501-516. doi:10.1080/03075070500249138

Bourdieu, P. (1977). Outline of a theory of practice. Cambridge: Cambridge University Press.

Bourdieu, P. (1984). Distinction: A social critique of the judgment of taste. London: Routledge \& Kegan Paul Ltd.

Bourdieu, P. (1985). The social space and the genesis of groups. Theory and Society, 14(6), 723-744. doi:10.1007/bf00174048

Bourdieu, P. (1986). Forms of capital. In J. G. Richardson (Ed.), Handbook of theory and research for the sociology of education (pp. 241-258). New York: Greenwood Press.

Bourdieu, P. (1991). Language and symbolic power. Cambridge: Polity Press.

Bourdieu, P. (1993). The field of cultural production. New York: Columbia University Press.

Bourdieu, P. (1996). The state nobility: Elite schools in the field of power. Cambridge: Polity Press.

Bourdieu, P. (2000). Pascalian meditations. Cambridge: Polity Press.

Bourdieu, P. (2011). On television. Cambridge: Polity Press.

Bourdieu, P., \& Wacquant, L. J. D. (1992). An invitation to reflexive sociology. Cambridge: Polity Press.

Boyatzis, R. E. (1998). Transforming qualitative information: Thematic analysis and code development. London: Sage. 
Mu et al.

Braun, V., \& Clarke, V. (2006). Using thematic analysis in psychology. Qualitative Research in Psychology, 3(2), 77-101. doi:10.1191/1478088706qp063oa

Brookes, M., \& Becket, N. (2011). Developing global perspectives through international management degrees. Journal of Studies in International Education, 15(4), 374-394. doi:10.1177/1028315309357944

Bullough, R. V., \& Pinnegar, S. (2001). Guidelines for quality in autobiographical forms of self-study research. Educational Researcher, 30(3), 13-21. doi:10.3102/0013189x030003013

Carilloa, M. R., Papagni, E., \& Sapio, A. (2013). Do collaborations enhance the high-quality output of scientific institutions? Evidence from the Italian Research Assessment Exercise. The Journal of SocioEconomics, 47, 25-36.

Collins, A., Brown, J. S., \& Holum, A. (1991). Cognitive apprenticeship: Making things visible. American Educator, 15(3), 6-11 \& 38-46.

Dahlgren, M. A., Grosjean, G., Lee, A., \& Nyström, S. (2012). The graduate school in the sky: Emerging pedagogies for an international network for doctoral education and research. In A. Lee \& S. Danby (Eds.), Reshaping doctoral education: International approaches and pedagogies (pp. 173-186). London: Routledge.

Dinkelman, T., Cuenca, A., Butler, B., Elfer, C., Ritter, J., Powell, D., \& Hawley, T. (2012). The influence of a collaborative doctoral seminar on emerging teacher educator-researchers. Action in Teacher Education, 34(2), 172-190.

Falls, L., Jara, T., \& Sever, T. (2009). Experiential workshop with educational leadership doctoral students: Managing affective reactions to organisational change. Journal of Leadership Education, 7(3), 219229. As found at http://leadershipeducators.org/Resources/Documents/jole/2009 winter/JOLE 7 3.pdf\#page=232

Freeman, R. B. (2010). Globalization of scientific and engineering talent: international mobility of students, workers, and ideas and the world economy. Economics of Innovation and New Technology, 19(5), 393406. doi:10.1080/10438590903432871

Freeman, S., \& Kochan, F. K. (2012). Academic pathways to university leadership: Presidents' descriptions of their doctoral education. International Journal of Doctoral Studies, 7, 93-124. Retrieved from http://ijds.org/Volume7/IJDSv7p093-124Freeman353.pdf

Gasset, O. Y. (1944). Mission of the university (H. L. Nostrand, Trans.). New Jersey, USA: Princeton University Press.

Henderson, K., Oakleaf, L., James, P., Swanson, J., Moore, A., Edwards, M., \& Hickerson, B. (2008). The experience of learning/teaching qualitative research approaches: An ethnographic autobiography. Schole: A Journal of Leisure Studies and Recreation Education, 23, 27-42.

Higher Education Institute of Southwest Jiaotong University. (2013). 教育部直属高校国际化水平排行榜 [Evaluation report on the internatonalisation of Chinese universities]. Chengdu, China: Higher Education Institute of Southwest Jiaotong University.

Hyatt, L., \& Williams, P. E. (2011). 21st century competencies for doctoral leadership faculty. Innovative Higher Education, 36(1), 53-66. doi:10.1007/s10755-010-9157-5

Jeong, S., Choi, J., \& Kim, J. (2011). The determinants of research collaboration modes: Exploring the effects of research and researcher characteristics on co-authorship. Scientometrics, 89(3), 967-983. doi:10.1007/s11192-011-0474-y

Kalaitzidakis, P., Mamuneas, T. P., Savvides, A., \& Stengos, T. (2004). Research spillovers among European and North-American economics departments. Economics of Education Review, 23(2), 191-202. doi:http://dx.doi.org/10.1016/j.econedurev.2003.07.001

Kanyi, T. K. (2009). Towards a marketing communication recruitment plan for the Rowan University educational leadership doctoral program. Rowan University. 
Lancho-Barrantes, B., Guerrero-Bote, V., \& Moya-Anegón, F. (2013). Citation increments between collaborating countries. Scientometrics, 94(3), 817-831. doi:10.1007/s11192-012-0797-3

Leask, B. (2007). International teachers and international learning. In E. Jones \& S. Brown (Eds.), Internationalising higher education (pp. 86-94). London: Taylor and Francis.

Lee, A., \& Danby, S. (Eds.). (2012). Reshaping doctoral education: International approaches and pedagogies. London: Routledge.

Lei, S., Gorelick, D., Short, K., Smallwood, L., \& Wright-Porter, K. (2011). Academic cohorts: Benefits and drawbacks of being a member of a community of learners. Education, 131(3), 497-504.

Leiper, J., Horn, E. R. V., Hu, J., \& Upadhyaya, R. C. (2008). Promoting cultural awareness and knowledge among faculty and doctoral students. Nursing Education Perspectives, 29(3), 161-164.

Li, M., Fox, J., \& Davis, J. (2013). Lesson studies in Chinese kindergartens. Educating Young Children, 19(1), 37-39.

Lunn, J. (2008). Global perspectives in higher education: Taking the agenda forward in the United Kingdom. Journal of Studies in International Education, 12(3), 231-254. doi:10.1177/1028315307308332

McVicar, A., Caan, W., Hillier, D., \& Munn-Giddings, C. (2006). A shared experience: An interdisciplinary professional doctorate in health and social care. Innovations in Education and Teaching International, 43(3), 211-222.

Mu, G. M., \& Dooley, K. (2015). Coming into an inheritance: Family support and Chinese heritage language learning. International Journal of Bilingual Education and Bilingualism, 18(4), 501-515. doi:10.1080/13670050.2014.928258

Mu, G. M., \& Jia, N. (2014). Rural dispositions of floating children within the field of Beijing schools: Can disadvantaged rural habitus turn into recognised cultural capital? British Journal of Sociology of Education. doi:10.1080/01425692.2014.939264

Mu, G. M., \& Strong, T. (2014). Negotiating identities through learning Chinese as a heritage language in Australia and beyond: The 'seen but unnoticed rule'. Paper presented at the BAICE 2014 Conference: Power, Politics, and Priorities for Comparative and International Education, Bath, UK.

Mu, G. M., Zheng, X., Jia, N., Li, X., Wang, S., Chen, Y., . . . Diezmann, C. (2013). Revisiting educational equity and quality in China through Confucianism, policy, research, and practice. The Australian Educational Researcher, 40(3), 373-389. doi:10.1007/s13384-013-0113-0

Nimer, M. (2009). The doctoral cohort model: Increasing opportunities for success. College Student Journal, 43(4), 1373-1379.

Niu, X. S. (2013). International scientific collaboration between Australia and China: A mixedmethodology for investigating the social processes and its implications for national innovation systems. Technological Forecasting and Social Change. doi:http://dx.doi.org/10.1016/j.techfore.2013.10.014

Pečlin, S., Južnič, P., Blagus, R., Sajko, M., \& Stare, J. (2012). Effects of international collaboration and status of journal on impact of papers. Scientometrics, 93(3), 937-948. doi:10.1007/s11192-012-0768-8

Pfotenhauer, S. M., Jacobs, J. S., Pertuze, J. A., Newman, D. J., \& Roos, D. T. (2013). Seeding change through international university partnerships: The MIT-Portugal Program as a driver of internationalization, networking, and innovation. Higher Education Policy, 26(2), 217-242. doi:http://dx.doi.org/10.1057/hep.2012.28

Queensland University of Technology. (2014). QUT Blueprint 4. Brisbane: QUT.

Rizvi, F. (2010). International students and doctoral studies in transnational spaces. In M. Walker \& P. Thomson (Eds.), The Routledge doctoral supervisor's companion: Supporting effective research in education and the social sciences (pp. 158-170). London: Routledge.

Simons, H. (2009). Case study research in practice. London: Sage. 
Spencer-Oatey, H. (2013). Maximizing the benefits of international education collaborations: Managing interaction processes. Journal of Studies in International Education, 17(3), 244-261. doi: $10.1177 / 1028315312454545$

State Council, P. R. C. (2010). 国家中长期教育改革和发展规划纲要(2010-2020 年) [State guidelines for medium- and long-term education reform and development plan (2010-2020)]. Beijing: State Council.

Stohl, M. (2007). We have met the enemy and he is us: The role of the faculty in the internationalization of higher education in the coming decade. Journal of Studies in International Education, 11(3-4), 359372. doi: $10.1177 / 1028315307303923$

Teichler, U. (2004). The changing debate on internationalisation of higher education. Higher Education, 48(1), 5-26. doi:10.2307/4151528

Teng, D. C.-E., Chen, N.-S., Kinshuk, \& Leo, T. (2012). Exploring students' learning experience in an international online research seminar in the Synchronous Cyber Classroom. Computers \& Education, 58(3), 918-930. doi:http://dx.doi.org/10.1016/j.compedu.2011.10.018

Universities Australia. (2013). An agenda for Australian higher education 2013-2016. Canberra: Universities Australia.

Vescio, V., Bondy, E., \& Poekert, P. E. (2009). Preparing multicultural teacher educators: Toward a pedagogy of transformation. Teacher Education Quarterly, 36(2), 5-24.

Williams, D., Simpson, M., \& Cunningham, J. (2010). Learning in online community: A model of doctorate level internet-enhanced education. Common Ground Journal, 7(2), 32-56.

Zhao, F., Bentley, T., Reames, E. H., \& Reed, C. (2002). Theory, research, and practice: bridging the gap in a doctoral candidate seminar. Auburn, Alabama: Auburn University/ERIC. Retrieved from http://eric.ed.gov/?id=ED470842

\section{Biographies}

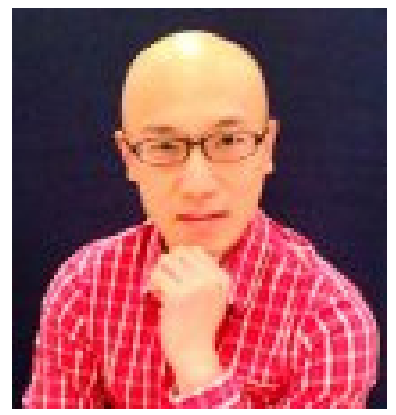

Dr Guanglun Michael Mu is Vice-Chancellor's Research Fellow at Queensland University of Technology, Australia. He grapples with diversity and inclusivity using sociological theories, Bourdieu's sociology in particular.

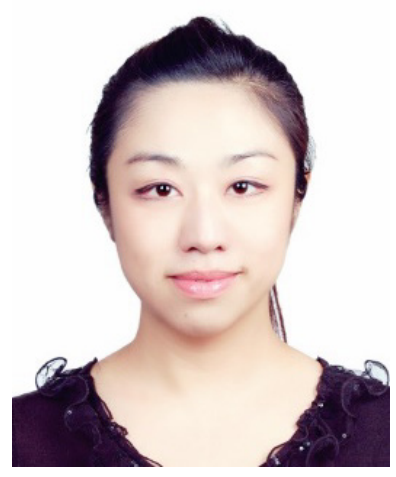

Dr Ning Jia is a Lecturer at Shenyang University. Her teaching and research interest is educational administration and organisational sociology. 

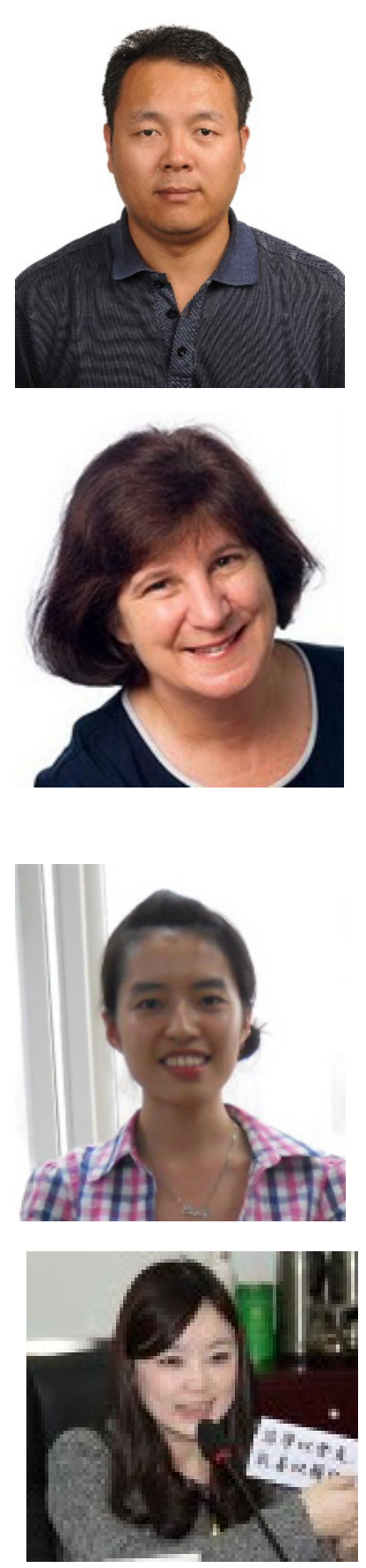

Mu-Chu Zhang is a PhD candidate at Beijing Normal University. Her current research interest mainly lies in the study of history of Chinese education in the twentieth century.

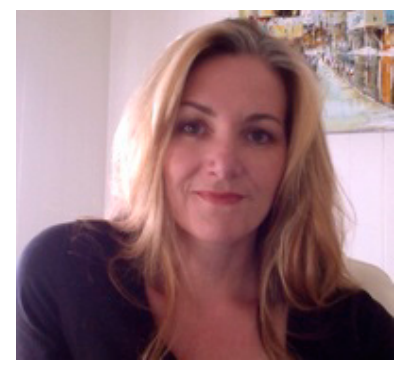

Xiao-Bo Shi is a PhD candidate at Beijing Normal University and a Lecturer at Henan Normal University. Her research focuses on the design of childcare centres and early childhood facilities.

Dr Hilary Hughes is an Associate Professor at Queensland University of Technology. She is an experienced information literacy educator.

Dr Yongbin Hu is a Lecturer at Jiangsu Normal University. He engages with smart learning, ICT leadership in K-12 education.
Dr Jennifer Alford is a Senior Lecturer in the Faculty of Education, Queensland University of Technology. Jennifer uses critical theory and discourse analysis to explore Education policy and practice. 


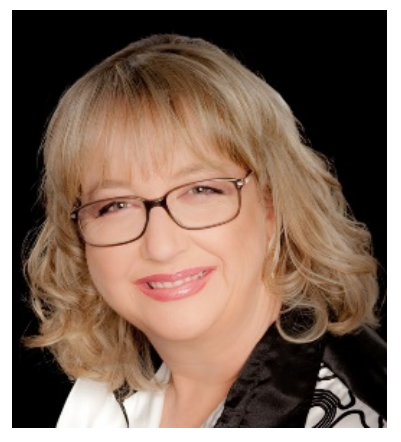

Dr Merilyn Carter is an educational consultant in mathematics and numeracy. She also works with the YuMiDeadly Centre at Queensland University of Technology, developing mathematics programs for indigenous and disadvantaged students.

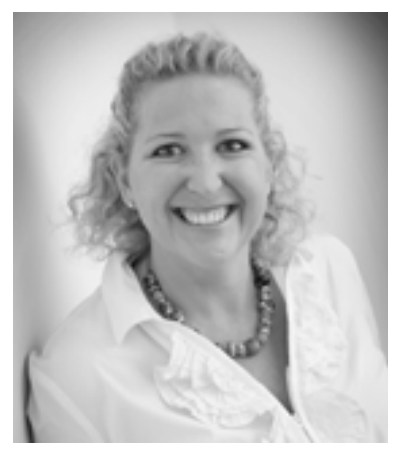

Dr Jillian Fox is a Senior Lecturer at the Australian Catholic University. Her teaching and research interests focus on preservice teacher transitions and young children's engagement with mathematics and technology.

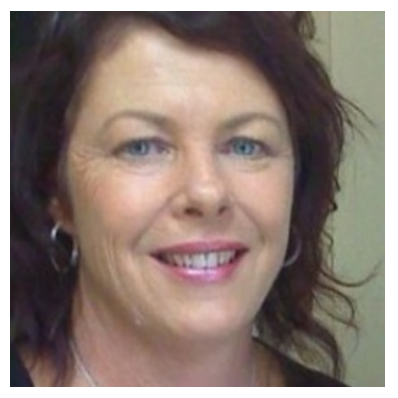

Dr Jennie Duke is a Lecturer in Inclusive Education at Queensland University of Technology. Her research and teaching interest is disabilities.

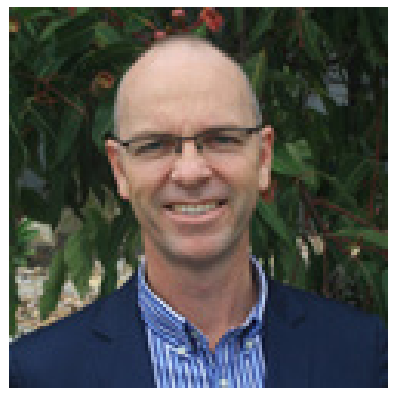

Dr Matthew Flynn has research interests in the innovative application of vocationalism, systems theory and collaboration. Extensive experience in organisational development across varied industries provides him with a well-grounded approach.

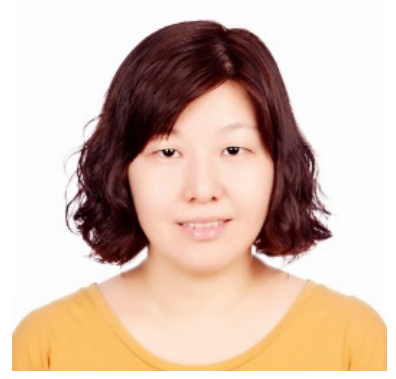

Huanhuan Xia is a $\mathrm{PhD}$ candidate at Beijing Normal University. Her current research mainly focuses on assessing higher education student learning outcomes in China. 